\title{
ОЦІНКА ПРОГНОЗУ МУЛЬТИФОКАЛЬНОЇ ВИСОКОДИФЕРЕНЦІЙОВАНОЇ ТИРЕОЇДНОЇ КАРЦИНОМИ ЗА СИСТЕМОЮ ТNМ
}

Н. Я. Кобринська

\author{
ДУ «Інститут ендокринології та обміну речовин ім. В. П. Комісаренка НАМН України»
}

\begin{abstract}
Проведено порівняльний аналіз моно- та мультифокальних високодиференційованих тиреоїдних карцином (папілярних та фролікулярних) за системою ТNМ. Всього проаналізовано 2208 випадків моносрокальних та 692 випадки мультифокальних уражень. В результаті проведеного аналізу доведено, що мультифокальні карциноми, на відміну від солітарних уражень, характеризуються більш агресивним перебігом. Багатофокусне ураження за рубриками Т, $\mathrm{N}$ та М з достовірністю на рівні не менше 99 \% мало більш високі індекси, ніж монофокальне. Головним висновком $€$ необхідність більш радикальної тактики лікування у цих випадках.
\end{abstract}

Ключові слова: рак щитоподібної залози, мультисрокальна карцинома, хірургічне лікування.

\section{ОЦЕНКА ПРОГНОЗА МУЛЬТИФОКАЛЬНОЙ ВЫСОКОДИФФЕРЕНЦИРОВАННОЙ ТИРЕОИДНОЙ КАРЦИНОМЫ ПО СИСТЕME TNM}

\author{
Н. Я. Кобринская \\ ГУ «Институт эндокринологии и обмена веществ им. В. П. Комиссаренко НАМН Украины»
}

\begin{abstract}
Проведен сравнительный анализ моно- та мультифокальных высокодиффференцированных тиреоидных карцином (папиллярных и фолликулярных) по системе TNM. Всего проанализировано 2208 случаев монофокальных и 692 случая мультифокальных поражений. В результате проведенного анализа доказано, что мультифокальные карциномы, в отличие от солитарных поражений, характеризуются более агрессивным течением. Многофрокусное поражение по рубрикам Т, N и М с достоверностью на уровне не меньше 99 \% имело более высокие индексы, чем монофрокальное. Главным выводом является необходимость более радикальной тактики лечения в этих случаях.
\end{abstract}

Ключевые слова: рак щитовидной железы, мультифрокальная карцинома, хирургическое лечение.

\section{EVALUATION OF PROGNOSIS IN MULTIFOCAL HIGHLY DIFFERENTIATED THYROID CARCINOMAS ACCORDING TO THE TNM SYSTEM}

\author{
SI «V. P. Komisarenko Institute of Endocrinology and Metabolism NAMS of Ukraine»
}

N. Ya. Kobrynska

\begin{abstract}
The comparative analysis of mono- and multifocal highly differentiated thyroid carcinoma (papillary and follicular) according to the TNM system was conducted. There were analyzed 2208 cases of monofocal and 692 cases of multifocal lesions in total. The analysis demonstrated that multifocal carcinomas, unlike solitary lesions, were characterized by a more aggressive course. Multicenter lesion by rubrics T, $\mathrm{N}$ and $\mathrm{M}$ with certainty at $99 \%$ and more had higher indices than monofocal. Thus, T2 stage was recorded at $20.4 \%$ of multifocal carcinomas versus $15.7 \%$ for monofocal. The difference in T3 stage was also significant $(22.4 \%$ vs. $18.8 \%$ respectively). In cases of T4 stage percent difference was $6.9 \%$ with $5.0 \%$ of multifocal and monofocal with thyroid carcinomas. N1a stage was recorded in $16.2 \%$ of cases of multifocal carcinomas compared with $13.7 \%$ for monofocal. Even more significant was the difference in N1b category - $15.7 \%$ among multifocal that only $8.7 \%$ of monofocal thyroid carcinomas. Distant metastases in patients with mono- and multifocal carcinoma were detected in isolated cases and this group of patients did not differ significantly from one another in such case $(p>0.05)$. The main conclusion is the need for more radical tactics of treatment in these cases.
\end{abstract}

Key words: thyroid cancer, multifocal carcinoma, surgical treatment.

(c) Н. Я. Кобринська 
Вступ. Якщо проблема раку щитоподібної залози (Щ3) вивчається вже протягом багатьох десятиріч, то мультифокальна папілярна тиреоїдна карцинома привернула увагу фахівців лише в останні роки. Вивчаються різні питання особливостей клінічного перебігу мультифокальної папілярної карциноми. У фаховій літературі приділяється особлива увага мультифокальності як фактору ризику появи метастазів у лімфатичних вузлах [14, 20], прогнозу одужання [16], рецидиву хвороби [6, 12] та більш агресивних ознак пухлини $[10,11]$. Автори роботи [5] дійшли висновку, що мультифокальний папілярний рак Щз є більш агресивним, ніж одиничне пошкодження.

У той же час експерти консенсусу з мультифокальної папілярної тиреоїдної карциноми на основі даних літератури зробили висновок про те, що прогностична значимість мультифокального пухлинного росту при папілярних карциномах, як і інших факторів ризику, залишається суперечливою [3].

У зв'язку з викладеним вище, метою дослідження була порівняльна оцінка основних показників агресивності злоякісного враження ЩЗ, лімфатичних вузлів та легенів у хворих на моно- та мультифокальну високодиференційовану тиреоїдну карциному.

Матеріали та методи дослідження. Для порівняльного аналізу злоякісності протікання рака ЩЗ у хворих на моно- та мультифокальну карциному були використані відповідні матеріали, викопійовані з медичної карти стаціонарного хворого (статформа №003/O), $з$ протоколами операцій та патогістологічних досліджень на 693 хворих на мультифокальну та на 2211 хворих на монофокальну папілярну тиреоїдну карциному, які лікувались в ДУ «Інститут ендокринології та обміну речовин ім. В. П. Комісаренка НАМН України» протягом 1999-2015 pp.

Порівнювались ознаки, які були прийняті нами за показники агресивності перебігу рака Щз. Це розмір пухлини ЩЗ, наявність регіонарних лімфатичних вузлів та наявність віддалених метастазів, які визначались за Міжнародною класифікацією пухлин (МКП) TNM в шостій редакції. Вивчалась також наявність метастазів в легенях хворих за даними радіойодтерапії.

Зведення даних за спеціальними таблицями здійснювалось на комп'ютері за допомогою програми Excel з пакету Microsoft Office.

Розраховувались екстенсивні показники, тобто частка хворих з тою чи іншою ознакою серед хворих на моно- та мультифокальну карциному. Достовірність різниці між порівнюваними показниками визначалась за методом хі-квадрат $\left(\chi^{2}\right)$ Пірсона.

Результати та їх обговорення. В таблиці 1 представлені дані про розподіл хворих на моно- та мультифокальну папілярну тиреоїдну карциному за величиною первинної пухлини ЩЗ. Як уже зазначалось, тут і далі розміри вузлів ЩЗ, ураження лімфатичних вузлів та віддалені метастази визначені за МКП ЩЗ (TNM) в шостій редакції.

Зазначимо, що ці фактори, як відомо, є визначальними для оцінки ступеню поширення злоякісного процесу та вибору тактики лікування.

Таблиця 1

Розподіл хворих на моно- та мультифокальну папілярну тиреоїдну карциному за величиною первинної пухлини Щз

\begin{tabular}{|c|c|c|c|c|c|c|}
\hline \multirow{3}{*}{$\begin{array}{c}\text { Розмір } \\
\text { пухлини (рубрика Т МКП) }\end{array}$} & \multicolumn{4}{|c|}{ Карцинома } & \multirow{3}{*}{$x^{2}$} & \multirow{3}{*}{$\mathrm{p}$} \\
\hline & \multicolumn{2}{|c|}{ монофокальна } & \multicolumn{2}{|c|}{ мультифокальна } & & \\
\hline & абс. & $\%$ & абс. & $\%$ & & \\
\hline $\begin{array}{l}\text { Пухлина до } 2 \text { см } \\
\text { в межах Щ3 (Т1) }\end{array}$ & 1348 & 61,1 & 348 & 50,3 & \multirow{4}{*}{26,95} & \multirow{4}{*}{$<0,01$} \\
\hline $\begin{array}{l}\text { Пухлина 2-4 см } \\
\text { в межах Щ3 (Т2) }\end{array}$ & 347 & 15,7 & 141 & 20,4 & & \\
\hline $\begin{array}{c}\text { Пухлина понад } 4 \text { см } \\
\text { в межах Щ3 (Т3) }\end{array}$ & 403 & 18,3 & 155 & 22,4 & & \\
\hline $\begin{array}{c}\text { Пухлини різних розмірів за межами } \\
\text { капсули Щ3 (Т4) } \\
\end{array}$ & 110 & 5,0 & 48 & 6,9 & & \\
\hline Усього & 2208 & 100,0 & 692 & 100,0 & - & - \\
\hline
\end{tabular}


Iз наведених в табл. 1 даних виходить, що 3 надійністю на рівні не менше 99 \% можна стверджувати, що за величиною розмірів пухлини в ЩЗ хворі на монофокальну і хворі на мультифокальну карциному суттєво розрізняються між собою. За отриманими даними мультифокальна карцинома достовірно характеризувалась більшими відсотками випадків стадій Т2-Т4, ніж монофокальна. Так, стадія Т2 була зафіксована у 20,4\% хворих на мультифокальну карциному порівняно $з$ 15,7\% хворих $з$ монофокальною. Різниця за стадією ТЗ була також достовірною (22,4\% порівняно з 18,8\% відповідно). У випадках стадії Т4 різниця відсотків становила 6,9\% при мультифокальних та 5,0\% при монофокальних тиреоїдних карциномах. Тільки в групі пухлин до 2 см перевага була за монофокальними пухлинами (61,1\%), на відміну від 50,3\% при мультифокальних. Таким чином, за нашими даними мультифокальні карциноми характеризуються в цілому більш високою стадією за класифікацією TNM, тобто виявляють більшу агресивність, щонайменше серед мешканців України. Такої ж думки дотримуються більшість авторів [5, 9, 13, 15, 21]. Але, хоча і в меншості, існують дані щодо відсутності достовірної різниці між моно- та мультифокальними карциномами [1, 7]. Здебільшого в роботах на основі грунтовних та об’ємних досліджень висловлюється думка щодо достовірного впливу на прогноз мультифокаль- них пухлин розміром понад 1 см, тоді як менші не мають такого достовірного впливу [2, 6, 18, 19].

Зазначимо, що при оцінці за розмірами максимального (при наявності декількох) вогнища було 3'ясовано, що за жодною з груп від менше 5 мм до 41 мм та більше не було виявлено достовірної переваги при порівнянні випадків моно- та мультифокальної карциноми. Це співпадає з думкою багатьох дослідників [1, 4, 17]. Хоча існує позиція щодо однозначного впливу розміру на виявлення мультифокального росту та агресивності тиреоїдних карцином $[12,21]$. За даними S. F. Кuо серед мультифокальних тиреоїдних карцином було виявлено 22 \% макро- та 19,5 \% мікрокарцином [18], що також доводить відсутність впливу розміру на наявність мультифокальності.

Дані табл. 2 дають уяву про ураження регіонарних лімфатичних вузлів у хворих на моно- та мультифокальну карциному.

Важливим, якщо не найважливішим, показником агресивності пухлини є наявність метастатичного ураження. Результати порівняльного аналізу моно- та мультифокальних тиреоїдних карцином (рубрика N за класифікацією TNM) наведено у табл. 2. Більшість з пацієнтів обох груп взагалі не мали метастазів на час операції, що є ще одним підтвердженням відносно сприятливого прогнозу високодиференційованих тиреоїдних карцином. Але випадки наявності ураження регіонарних лімфатичних вузлів достовірно частіше виявля-

Таблиця 2

\section{Розподіл хворих на моно- та мультифокальну високодиференційовану тиреоїдну карциному за локалізацією уражень реґіонарних лімфатичних вузлів}

\begin{tabular}{|c|c|c|c|c|c|c|}
\hline \multirow{3}{*}{$\begin{array}{c}\text { Локалізація уражень } \\
\text { periонарних лімфовузлів } \\
\text { (рубрика N МКП) }\end{array}$} & \multicolumn{4}{|c|}{ Карцинома } & \multirow{3}{*}{$x^{2}$} & \multirow{3}{*}{$\mathrm{p}$} \\
\hline & \multicolumn{2}{|c|}{ монофокальна } & \multicolumn{2}{|c|}{ мультифокальна } & & \\
\hline & абс. & $\%$ & абс. & $\%$ & & \\
\hline $\begin{array}{c}\text { Метастази в регіонарних лімфовуз- } \\
\text { лах не виявлені (NX+NO) }\end{array}$ & 1713 & 77,6 & 471 & 68,1 & \multirow{3}{*}{26,95} & \multirow{3}{*}{$<0,01$} \\
\hline $\begin{array}{c}\text { Метастази в регіонарних лімфовуз- } \\
\text { лах VI рівня (N1a) }\end{array}$ & 302 & 13,7 & 112 & 16,2 & & \\
\hline $\begin{array}{c}\text { Ураження інших шийних лімфовуз- } \\
\text { лів з обох боків або з протилежного } \\
\text { боку (N1b) }\end{array}$ & 193 & 8,7 & 109 & 15,7 & & \\
\hline Усього & 2208 & 100,0 & 692 & 100,0 & - & - \\
\hline
\end{tabular}




\section{Розподіл хворих на моно- та мультифокальну папілярну карциному за наявністю віддалених метастазів}

\begin{tabular}{|c|c|c|c|c|c|c|}
\hline \multirow{3}{*}{$\begin{array}{c}\text { Наявність } \\
\text { віддалених метастазів } \\
\text { (рубрика М МКП) }\end{array}$} & \multicolumn{4}{|c|}{ Карцинома } & \multirow{3}{*}{$x^{2}$} & \multirow{3}{*}{$\mathrm{p}$} \\
\hline & \multicolumn{2}{|c|}{ монофокальна } & \multicolumn{2}{|c|}{ мультифокальна } & & \\
\hline & абс. & $\%$ & абс. & $\%$ & & \\
\hline $\begin{array}{c}\text { Метастази не виявлені } \\
(\mathrm{MX}+\mathrm{MO})\end{array}$ & 2200 & 99,6 & 688 & 99,4 & \multirow{2}{*}{0,59} & \multirow{2}{*}{$>0,05$} \\
\hline Метастази виявлені (МI) & 8 & 0,4 & 4 & 0,6 & & \\
\hline Усього & 2208 & 100,0 & 692 & 100,0 & - & - \\
\hline
\end{tabular}

лися в групі мультифокальних карцином. Зокрема, стадія N1а зафіксована у 16,2 \% випадків мультифокальних карцином порівняно з 13,7 \% при монофокальних. Ще більш суттєвою виявилась різниця за категорією N1b - 15,7 \% серед мульти- та лише 8,7 \% серед монофокальних тиреоїдних карцином. Переважна більшість дослідників також відмічають наявність регіонарних метастазів однією 3 характерних ознак мультифокального ураження $[4,8,12,21]$.

В таблиці 3 представлені дані про наявність у спостережених хворих обох груп віддалених метастазів.

Як видно із табл. 3, у представленої більшості спостережених хворих віддалені метастази не були виявлені. Віддалені метастази у хворих на монота мультифокальну карциному виявлялися в поодиноких випадках і з цього приводу порівнювані групи хворих між собою суттєво не відрізнялись (р > 0,05).

Висновки. Отже, із представлених вище даних можна зробити висновок, що особливостями патогістологічного протікання хвороби у пацієнтів 3 мультифокальною карциномою на фоні хворих 3 монофокальною карциномою є більш часте виявлення пухлинних вузлів в ЩЗ більших розмірів та метастази в регіонарні лімфатичні вузли шиї з обох боків або з протилежного боку. Також у них частіше виявляються три і більше метастазів в легенях. Всі ці особливості свідчать про те, що хвороба у пацієнтів з мультифокальною карциномою перебігає значно складніше, ніж у пацієнтів з монофокальною карциномою. Тобто монофокальність $€$ вираженим фактором ризику більш агресивного перебігу хвороби.

\section{Література.}

1. Ивахно И. В. Основные морфологические признаки метастазирующих папилярных микрокарцином щитовидной железы / И. В. Ивахно // Вісник проблем біології і медицини. - 2014. - Т. 3, № 4. - С. 266-270.

2. Маколина Н. П. Современная парадигма послеоперационного ведения больных с дифференцированным раком щитовидной железы / Н. П. Маколина, Н. М. Платонова // Клиническая и экспериментальная тиреоидология. - 2011. - Т. 2, № 3. - С. 8-21.

3. Мультифокальная папиллярная тиреоидная карцинома. Консенсус Европейского общества эндокринных хирургов (Workshop «Surgery of Thyroid Cancer», ESES, Berlin, Germany, May 23-25, 2013) (обзор литературы и собственные данные) / А. Е. Коваленко, М. Ю. Болгов, П. П. Зиныч, Н. Я. Кобринская // Ендокринологія. - 2015. - T. 20, № 4. - C. 721-734.

4. Analysis of differential BRAF (V600E) mutational status in multifocal papillary thyroid carcinoma: evidence of independent clonal origin in distinct tumor foci / S. Y. Park, Y. J. Park, Y. J. Lee [et al.] // Cancer. - 2006. - Vol. 107, No. 8. - P. 1831-1838.

5. Clinical characteristics and surgical resection of multifocal papillary thyroid carcinoma: 168 cases / G. Huang, X. Tian, Y. Li, F. Ji // Int. J. Clin. Exp. Med. - 2014. - Vol. 15, No. 12. - P. 5802-5807.

6. Drucker W. D. Papillary microcarcinoma of the thyroid/W. D. Drucker, R. J. Robbins // Practical management of thyroid cancer: a multidisciplinary approach / E. L. Mazzaferri, C. Harmer, U. K. Mallick, P. Kendall-Taylor (Eds.). - London : Springer, 2006. - P. 371-389.

7. Gemsenjäger E. W. Multifocal papillary thyroid carcinoma / E. W. Gemsenjäger, P. U. Heiz, I. Schweizer // New Engl. J. Med. - 2005. - Vol. 353. - P. 1067-1068.

8. Hemithyroidectomy increases the risk of disease recurrence in patients with ipsilateral multifocal papillary thyroid carcinoma / X. Li, C. Zhao, D. Hu [et al.] // Oncol. Lett. - 2013. - Vol. 5, No. 4. - P. 1412-1416.

9. Multifocality in well-differentiated thyroid carcinomas calls for total thyroidectomy / H. M Mazeh, Y. Samet, 
D. Hochstein [et al.] // Am. J. Surg. - 2011. - Vol. 201, No. 6. - P. 770-775.

10. Multifocal papillary thyroid cancer increases the risk of central lymph node metastasis / A. Al Afif, B. A. Williams, M. H. Rigby [et al.] // Thyroid. - 2015. - Vol. 25, No. 9. P. 1008-1012.

11. Number of tumor foci predicts prognosis in papillary thyroid cancer / N. Qu, L. Zhang, Q. H. Ji [et al.] // BMC Cancer. - 2014. - Vol. 4. - P. 914

12. Pediatric patients with multifocal papillary thyroid cancer have higher recurrence rates than adult patients: a retrospective analysis of a large pediatric thyroid cancer cohort over 33 years / Y. A. Leel, H. W. Jung, H. Y. Kim [et al.] // J. Clin. Endocrinol. Metab. - 2015. - Vol. 100, No. 4. - P. 1619-1629.

13. Risk factors for central lymph node metastasis in CNO papillary thyroid carcinoma: a systematic review and metaanalysis / W. Sun, X. Lan, H. Zhang [et al.] // PLoS One. - 2015. - Vol. 10, No. 10. - e0139021.

14. Risk of lymph node metastases in miltifocal papillary thyroid cancer associated with Hashmoto's thyroiditis / A. Konturek, V. Barzynsky, W. Nowak, W. Wierzchowski // Langenbeck's Arch. Surg. - 2014. - Vol. 399, No. 2. -. P. 229-236.

15. Role of prophylactic central compartment lymph node dissection in clinically N0 differentiated thyroid cancer patients: analysis of risk factors and review of modern trends / G. Conzo, E. Tartaglia, N. Avenia [et al.] // World J. Surg. Oncol. - 2016. - Vol. 14. - P. 149.

16. Rubenfeld S. Prognosis of patients with papillary or follicular thyroid cancer [Electronic resource] / S. Rubenfeld // ThyCa: Thyroid Cancer Survivors’ Association; Free Newsletter and Unformation Packet (website). - October 23, 2006. - Retrieved from: http://www.thyca.org/pap-fol/ treatment/prog/

17. Pitt S. C. Contralateral papillary thyroid cancer: does size matter? / S. C. Pitt, R. S. Sippel, H. Chen // Am. J. Surg. - 2009. - Vol. 197, No 3. - P. 342-347.

18. Prognosis of multifocal papillary thyroid carcinoma [Electronic resource] / S. F. Kuo, S. F. Lin, T. C. Chao [et al.] // International Journal of Endocrinology. - 2013. - Vol. 2013. - ID 809382. - Retrieved from : http://www.hindawi. com/iournals/ije/2013/809382.

19. Prognostic significance of tumor multifocality in papillary thyroid carcinoma and its relationship with primary tumor size: a retrospective study of 2,309 consecutive patients / K. J. Kim, S. M. Kim, Y. S. Lee [et al.] // Ann. Surg. Oncology. - 2015. - Vol. 22, No, 1. - P. 25-31.

20. Thyroid cancer: Papillary Thyroid Cancer (PTC) [Electronic resource] / The American Association of Endocrine Surgeons (patient education site). - Retrieved from : http://endocrinediseases.org/thyroid/cancer_ papillary.shtml

21. Total surface area is useful for differentiating between aggressive and favorable multifocal papillary thyroid carcinomas / J. S. Pyo, J. H. Sohn, G. Kang [et al.] // Yonsei Med. J. - 2015. - Vol. 56, No. 2. - P. 335-361.

\section{References.}

1. Ivakhno, I. V. (2014). Osnovnye morfologicheskie priznaki metastaziruyushchikh papilyarnykh mikrokartsinom shchitovidnoi zhelezy [The main morphological features of metastatic papillary thyroid microcarcinomas]. Visnik problem biologiï i meditsini (Biology and Medicine Issues Review), 3(4) [In Russian].

2. Makolina, N. P., Platonova, N. M. (2011). Sovremennaya paradigma posleoperatsionnogo vedeniya bol'nykh $\mathrm{s}$ differentsirovannym rakom shchitovidnoi zhelezy [The modern paradigm of the postoperative management of patients with differentiated thyroid cancer]. Klinicheskaya i eksperimental'naya tireoidologiya (Clinical and experimental thyroidology), 2(3) [In Russian].

3. Kovalenko, A. E., Bolgov, M. Yu., Zinych, P. P., Kobrinskaya, N. Ya. (2015). Mul'tifokal'naya papillyarnaya tireoidnaya kartsinoma. Konsensus Yevropeiskogo obshchestva endokrinnykh khirurgov [Multifocal papillary thyroid carcinoma: a consensus report of the European Society of Endocrine Surgeons] (Workshop «Surgery of Thyroid Cancer», ESES, Berlin, Germany, May 23-25, 2013) (literatury rewiew and own data). Endokrinologiya (Endocrinology), 20(4) [In Ukrainian].

4. Park, S. Y., Park, Y. J., Lee, Y. J., Lee, H. S., Choi, S. H., Choe, G., Jang, H. C., ... Cho, B. Y. (2006.). Analysis of differential BRAF (V600E) mutational status in multifocal papillary thyroid carcinoma: evidence of independent clonal origin in distinct tumor foci. Cancer, 107(8). doi: 10.1002/ cncr.22218

5. Huang, G., Tian, X., Li, Y., Ji, F. (2014). Clinical characteristics and surgical resection of multifocal papillary thyroid carcinoma: 168 cases. Int. J. Clin. Exp. Med., 15(12). 6. Drucker, W. D., Robbins, R. J. (2006). In: E. L. Mazzaferri, C. Harmer, U. K. Mallick, P. Kendall-Taylor (Eds.). Papillary microcarcinoma of the thyroid. In Practical management of thyroid cancer: a multidisciplinary approach (pp. 371-389). London: Springer.

7. Gemsenjäger, E. W., Heiz, P. U., Schweizer, I. (2005). Multifocal papillary thyroid carcinoma. New Engl. J. Med., 353. doi: 10.1056/NEJMc051872

8. Li, X., Zhao, C., Hu, D., Yu, Y., Gao, J., Zhao, W, Gao, M. (2013). Hemithyroidectomy increases the risk of disease recurrence in patients with ipsilateral multifocal papillary thyroid carcinoma. Oncol. Lett., 5(4). doi: 10.3892/ ol.2013.1202

9. Mazeh, H. M, Samet, Y., Hochstein, D., Mizrahi, I., Ariel, I., Eid, A., Freund, H. R. (2011). Multifocality in well-differentiated thyroid carcinomas calls for total thyroidectomy. Am. J. Surg., 201(6). doi: 10.1016/j. amjsurg.2010.03.004

10. Al Afif, A., Williams, B. A., Rigby, M. H., Bullock, M. J., Taylor, S. M, Trites, J., Hart, R. D. (2015). Multifocal papillary thyroid cancer increases the risk of central 
lymph node metastasis. Thyroid, 25(9). doi: 10.1089/ thy.2015.0130.

11. Qu, N., Zhang, L., Ji, Q. H., Zhu, Y. X., Wang, Z. Y., Shen, Q., Wang, Y., Li, D. S. (2014). Number of tumor foci predicts prognosis in papillary thyroid cancer. BMC Cancer, 4. doi: 10.1186/1471-2407-14-914

12. Leel, Y. A., Jung, H. W., Kim, H. Y., Choi, H., Kim, H. Y., Hah, J. H., Park, D. J. ... Park, Y. J. (2015). Pediatric patients with multifocal papillary thyroid cancer have higher recurrence rates than adult patients: a retrospective analysis of a large pediatric thyroid cancer cohort over 33 years. J. Clin. Endocrinol. Metab., 100(4). doi: 10.1210/jc.2014-3647

13. Sun, W., Lan, X., Zhang, H., Dong, W., Wang, Z., He, L., Zhang, T., S. Liu. (2015). Risk factors for central lymph node metastasis in CN0 papillary thyroid carcinoma: a systematic review and meta-analysis. PLoS One, 10(10). doi: 10.1371/journal.pone.0139021

14. Konturek, A. , Barzynsky, V., Nowak, W. , Wierzchowski, W. (2014). Risk of lymph node metastases in miltifocal papillary thyroid cancer associated with Hashmoto's thyroiditis. Langenbeck's Arch. Surg., 399(2). doi: 10.1007/ s00423-013-1158-2

15. Conzo, G., Tartaglia, E., Avenia, N., Calò, P. G., de Bellis, A., Esposito, K., Gambardella, C., ... Bellastella, G. (2016). Role of prophylactic central compartment lymph node dissection in clinically N0 differentiated thyroid cancer patients: analysis of risk factors and review of modern trends. World J. Surg. Oncol., 14. doi: 10.1186/s12957016-0879-4.
16. Rubenfeld, S. (2006, October 23). Prognosis of patients with papillary or follicular thyroid cancer ThyCa: Thyroid Cancer Survivors' Association ; Free Newsletter and Unformation Packet. - Retrieved from: http://www.thyca. org/pap-fol/treatment/prog/

17. Pitt, S. C., Sippel, R. S., Chen, H. (2009). Contralateral papillary thyroid cancer: does size matter? Am. J. Surg., 197(3). doi: 10.1016/j.amjsurg.2008.09.011.

18. Kuo, S. F., Lin, S. F., Chao, T. C., Hsueh, C., Lin, K. J., Lin, J. D. (2013). Prognosis of multifocal papillary thyroid carcinoma. International Journal of Endocrinology, 2013. Retrieved from http://www.hindawi.com/iournals/ ije/2013/809382

19. Kim, K. J., Kim, S. M., Lee, Y. S., Chung, W. Y., Chang, H. S., Park, C. S. (2015). Prognostic significance of tumor multifocality in papillary thyroid carcinoma and its relationship with primary tumor size: a retrospective study of 2,309 consecutive patients. Ann. Surg. Oncology, 22(1). doi: 10.1245/s10434-014-3899-8

20. Thyroid cancer: Papillary Thyroid Cancer (PTC). The American Association of Endocrine Surgeons. [Patient education site]. Retrieved from http://endocrinediseases. org/thyroid/cancer_papillary.shtml

21. Pyo, J. S., Sohn, J. H., Kang G., Kim, D. H., Yun, J. (2015). Total surface area is useful for differentiating between aggressive and favorable multifocal papillary thyroid carcinomas. Yonsei Med. J., 56(2). doi: 10.3349/ ymj.2015.56.2.355 